\title{
MANAGING LOCAL RESOURCES TO IMPROVE COMMUNITY EMPOWERMENT AND REDUCE POVERTY
}

\author{
Wahyuningsih*, Husnah \\ Faculty of Economy and Business, Tadulako University, Indonesia \\ *E-mail: ayu wningsih@yahoo.com
}

\begin{abstract}
This study aims to build a model describing the relationships among local resources management strategy, community empowerment, and poverty alleviation. This is a conceptual paper describing a key role of local resources to improve the skill of local community which lead to reduce poverty. Well managed local resources utilizing technology might increase value added and improve the income of society. It is argued that imperfectly imitable and non-substitutable local resources contribute to society economy improvement, therefore it will have a greater impact on poverty reduction. Theoretical contribution of this study is to enlarge body of knowledge in the field of strategic management. Meanwhile, managerial implications of this study can be applied by small medium enterprises (SME) and stakeholders to manage local resources and solve poverty problems.
\end{abstract}

\section{KEY WORDS}

Local resources, community, empowerment, poverty.

The utilization of local resources as a competitive advantage has been attracting numerous academics and practitioners for the last few years (e.g. Tokuda, 2005; Barney, 2001). One of those theories that very fascinating is Resourced-Based View (RBV) which classified as a substantial approach to manage resources and capabilities strategically. However, much debate have been addressed to criticize RBV by arguing that it does not presently appear to meet the empirical content criterion required of a theoretical system (Priem and Butler, 2001; McKelvey, 1997; Hunt, 1991; Bacharach, 1989). Priem and Butler (2001) have provided some suggestions for where and how the RBV may be able to contribute. They point out that he greatest potential likely will only be realized through complementary and integrated use of the RBV together with other, demand-oriented perspectives. The existence of RBV in strategic management considered as a key driver and capability of firms to achieve competitive advantages (Yang et al, 2009; Yasemin et al, 2006). Capabilities and all resources may be utilized as tools to determine competitiveness position in the market. This is in line with the argument of Galunic and Rodan (1998) who point out that competitive advantage of a firm might be derived from its resources. To be a source of sustained competitive advantage for a firm, resources must be valuable and rare, as well as inimitable and non-substitutable by rivals (Kariuki and Kilika, 2017).

Although there have been several researchers investigating RBV (e.g. McKelvey, 1997; Yang et al, 2009), their locus is limited on firms and big companies. More precisely, lack of RBV research has been conducted and implemented in the context of community empowerment and poverty reduction. Hence, the most critical question is how local resources that imperfectly imitable and non-substitutable provide contribution to empower community and reduce poverty. Although community empowerment has been discussed by several management scholars, little empirical work has been performed. Therefore, there is a need to investigate local resources using RBV theory approach which is integrated with local community empowerment and poverty alleviation.

\section{LITERATURE REVIEW}

Local Resources Management. The popularity of the resource-based "view" (RBV) of strategic management is manifest in its rapid diffusion throughout the strategy literature 
(Priem and Butler, 2001). This theory has been developed and studies as the basic for managing local resources to generate competitive advantage. To do so, a resource must provide economic value and must be presently scarce, difficult to imitate, non-substitutable, and not readily obtainable in factor markets (Powell, 1992).

Resource-based theory attributes advantage in an industry to a firm's control over bundles of unique material, human, organizational and locational resources and skills that enable unique value-creating strategies (Rindova and Fombrun, 1999). Hence, firms will generate sustained competitive advantage, gain higher profit and better performance.

Community Empowerment. Concepts of empowerment may vary according to the necessity to explore and explain diverse contexts (Eyben et al, 2006). In the field of management studies, concept of empowerment among both management researchers and practitioners has been reviewed thoroughly by some scholars (e.g. Block, 1991; Conger and Kanungo, 1988). Empowerment is defined as a process of enhancing feelings of self-efficacy among organizational members through the identification of conditions that foster powerlessness and through their removal by both formal organizational practices and informal techniques of providing efficacy information (Conger and Kanungo, 1988).

Empowerment is simultaneously a consequence and a process of development at individual or community scales (Rappaport, 1987). Empowerment is both a value orientation for working in the community and a theoretical model for understanding the process and consequence of efforts to exert control and influence over decisions that affect one's life, organizational functioning, and the quality of community life" (Perkins and Zimmerman, 1995).There are four dimensions of empowerment at individual and community scales put forward by Constantino et al (2012) namely psychological, social, economic, and political. Many interpretations of community empowerment are based on understandings of this concept as either as a process or as an outcome (Bernstein et al, 1994). Through the process of empowerment, communities are able to assume power to act effectively to change their lives and environment. The community empowerment process promotes the participation of people, organizations and communities for increased individual and community control, political efficacy, improved quality of life and social justice (Laverack and Wallerstein, 2001)

Poverty. The meaning of poverty may be intuitively obvious, but its measurement is complex (Adams et al, 2004). Poverty means different things to different people. However, common definitions are based on monetary (such as per-capita income) or nonmonetary (such as health or mortality) criteria, although broader approaches have been suggested (Sen, 2001). Poverty is a multi-dimensional concept implying lack of income, lack of resources and deprivation of means of livelihood.

Bradshaw (2007) examines theories of poverty place its origin from individual deficiencies, cultural belief systems that support subcultures in poverty, political-economic distortions, geographical disparities, or cumulative and circumstantial origins. People who live in poor conditions being mainly involved in livestock and agricultural activities, they face many challenges, including a lack of access to the market, inadequate skills, illiteracy, droughts, and financial problems (Ramimi, 2015). To overcome these problems, it requires proper identifications of the poor including their characteristics and survival strategies (Elijah and Ogunlade, 2006).

\section{METHODS OF RESEARCH}

The main purpose of this paper is to build a model integrating local resources management, community empowerment, and poverty reduction. Although previous studies has described these constructs (e.g. Narayan, 2002; Tokuda, 2005), but lack of research investigated relationships those three constructs in a comprehensive model. To propose hypotheses of this study, review on literature has been conducted to fulfill requirements to be tested using structural equation modeling.

Measures used in this study employ existing literature. The construct of local resources management is measured using multi-item scales adapted from Hitt et al (2011). The 
measures consist of tangible resources (physical evidence, financial resources, and natural resources) and intangible resources (human capital, organizational capital, and relational capital). Measures for community empowerment are based upon the existing literature put forward by Narayan (2002). The measures are divided into four elements of empowerment including access to information, inclusion and participation, accountability, and local organizational capacity. Poverty is measured using monetary (income, purchasing power) and nonmonetary criteria (health, education) adapted from Sen (2001).

\section{DISCUSSION OF RESULTS}

Local resources management and community empowerment. Local resources can be utilized as a source of competitive and comparative advantage if they are managed professionally. In doing so, communities in that area are required to improve their capabilities and skills. Hence, community empowerment is viewed as a process rather than as an outcome, which is most consistently determined in the literature. By measuring community empowerment as a process, it is possible to monitor the interaction between capacities, skills and resources at the individual and organizational levels (Laverack and Wallerstein, 2001). Therefore, managing local resources is a very important aspect to empower community.

In line with the above argument, Constantino et al (2012) have assessed four types of scales that facilitated local empowerment included the value of natural resources, rights to trade and manage resources, political organization of communities, and collaboration by stakeholders. They point out that managing natural resources in a positive way might improve community empowerment. In addition, Laverack and Wallernstein (2001) identified factors influencing community empowerment namely participation, leadership, problem assessment, and organizational structure. Lack of community capabilities can affect the failure of community empowerment (Adamson, 2010). His findings identify major barriers to the achievement of community empowerment including issues of community capacity, institutional capacity, organizational cultures and regulatory frameworks. These scholars believe that local resources that are well managed and traded will improve community empowerment. Therefore, it is proposed that "local resources management positively influences community empowerment".

Community empowerment and poverty reduction. Community empowerment has become a popular topic in many areas and it has been implemented as one of strategies to reduce poverty. Although no one theory explains all instances of poverty, Bradshaw (2007) has examined how community development practices that address the complex and overlapping sources of poverty more effectively reduce poverty compared to programs that address a single theory. In this case, poverty needs to be addressed using approach from various background of study. This is due to poverty is a multifaceted concept which include social, economic, and political elements.

Parallel with the above argument, Ramimi (2015) suggested community empowerment as a solution to poverty reduction. When people become more empower, their capabilities and skills are getting higher, and therefore they tend to achieve better education, health, and economy level. More precisely, community will earn better income and live in enhanced conditions. This is also supported by Narayan (2002) who point out that community empowerment is a useful approach to overcome poverty problems in many countries. Based on these studies, it is proposed that "community empowerment positively influences poverty reduction".

Local resources management and poverty reduction. Local resources should be utilized and managed in proper, wise and professional ways. The resources include both tangible and intangible assets such as natural resources, human capital, and relational capital. When local resources are well managed, the product can compete in the markets not only in domestic markets but also in global markets. This is in agreement with Collis' study (1991) that examined the contribution of local resources to global competition in particular and to strategic management in general. 
Moreover, Moser (1998) has investigated how asset management affects household poverty and vulnerability. Those assets consisting of tangible and intangible assets will provide benefits to community if they are well managed. Hence, local resources management will impact on economic development which in turn increase income and reduce poverty. Therefore, it is proposed that "local resources management positively influences poverty reduction".

Based on the above discussion, a proposed model of study can be figured out as bellow:

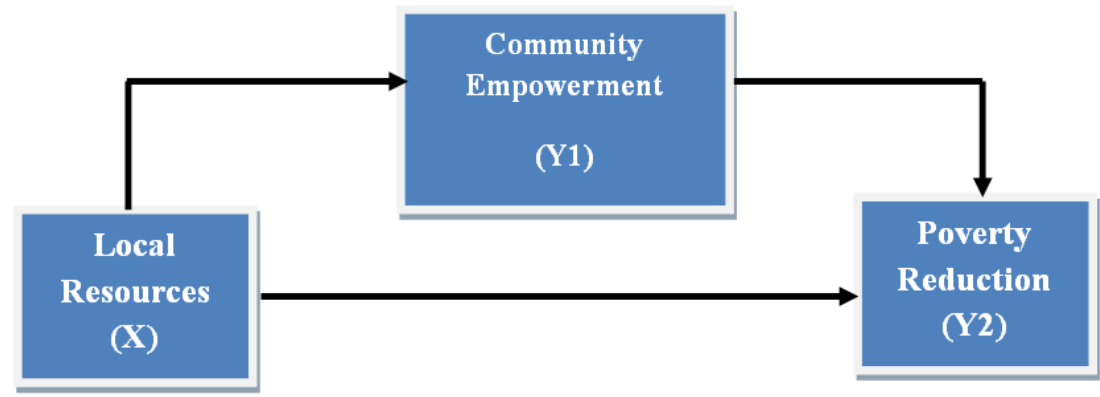

Figure 1 - Model of Study

\section{CONCLUSION}

Poverty is a major problem across country, specifically in developing countries. Academics in all background of study are challenged to provide contributions in reducing poverty. In other words, poverty problems need to be overcome using multi discipline approach. In an attempt to contribute to this issue, this paper suggests some proposed hypotheses to be tested in empirical study based on literature review.

This paper has also discussed the importance of community empowerment for reducing poverty. To become empower, communities need to improve their capabilities and skills through local resources management. They are trained to be more entrepreneurs and well informed to get an access to information and technology. To sum up, managing local resources is a useful approach for empowering community that lead to alleviating poverty.

\section{REFERENCES}

1. Adams, W., Aveling, R., Brockington, D., Dickson, B., Elliott, J., Hutton, J., Roe, D., Vira, B., Wolmer, W. (2004), Biodiversity Conservation and the Eradication of Poverty, 306, 146.

2. Adamson, D. (2010). Community empowerment: identifying the barriers to purposeful citizen participation, International Journal of Sociology and Social Policy, 30(3/4), 114126.

3. Bacharach, S. B. (1989), Organizational Theories: Some Criteria for Evaluation, Academy of Management Review, 14 (4), 496-515.

4. Barney, 2001. Is the Resouce Based View a Useful Perspective for Strategic Management Research? Yes.,Academy of Management Review, 26 (1), 41-56.

5. Bernstein, E., Wallerstein, N., Braithwaite, R., Gutierrez., L, Labonte, R., and Zimmerman, M. 1994. Empowerment forum: a dialogue between guest editorial board members, Health Education Quarterly, 21, 281-294.

6. Block, P., (1991). The Empowered Manager, Jossey-Bass Inc., California.

7. Bradshaw, Ted. (2007). Theories of Poverty and Anti-Poverty Programs in Community Development, Journal Community Development, 8/1, 7-25.

8. Collis, D. J. (1991). A resource-based analysis of global competition: The case of the bearings industry, Strategic Management Journal, 12(Summer Special Issue): 49-68.

9. Conger, J.A. and Kanungo, R.N. (1988). The empowerment process: integrating theory and practice, The Academy of Management Review, 13(3), 471-482. 
10. Elijah, $O$ and Ogunlade, I. 2006. Analysis of the uses of information and communication technology for gender empowerment and sustainable poverty alleviation in Nigeria, International Journal of Education \& Development Using ICT, 2/3. 1-25.

11. Eyben, R., C. Harris, and J. Pettit. 2006. Introduction: exploring power for change. IDS Bulletin 37(6):1-10.

12. Hitt, M.A.. R.D., Ireland \& R.E., Hoskisson. 2011. Strategic management: Competitiveness and globalization: Concepts. Ninth Edition.USA: South-Western Cengage Learning.

13. Hunt, S. D. (1991), Modern Marketing Theory: Critical Issue in the Philosophy of Marketing Science, Cincinnati, OH: South-Western Publishing.

14. Kariuki, J. and Kilika, J. (2017), Organization Capability, Innovation and Competitive Advantage: An Integrative Theoretical Framework Review of Literature, The International Journal of Business and Management, 5(2), 42-51.

15. Laverack, G. and Wallerstein, N., (2001). Measuring community empowerment: a fresh look at organizational domains, Health Promotion International, 16(2), 179-185.

16. McKelvey, B. (1997), Quasi-Natural Organization Science, Organization Science, 8 (4), 352-380.

17. Moser, C. 1998, The asset vulnerability framework: Reassessing urban poverty reduction strategies, World Development, 26(1), 1-19.

18. Narayan, D. (2002). Empowerment and Poverty Reduction: A Sourcebook. The World Bank, Washington DC.

19. Perkins, Douglas D. \& Zimmerman, Marc A. (1995). Empowerment Theory, Research, and Application. American Journal of Community Psychology, 23(5), 569-579.

20. Powell, T. C. (1992). Strategic planning as competitive advantage, Strategic Management Journal, 13, 551-558.

21. Priem, R. L., and J. E. Butler (2001), "Is the Resource-Based "view" a Useful Perspective for Strategic Management Research?" Academy of Management Review, 26 (1), 22-40

22. Rahimi, R.A.F., (2015). Towards community empowerment for poverty reduction in rural Afghanistan, Journal of Asia Pacific Studies, 34, 33-42.

23. Rappaport, J. (1987). Terms of empowerment/exemplars of prevention: toward a theory for community psychology. American Journal of Community Psychology 15(2), 121-148.

24. Rindova, V. P., and Fombrun, C. J. (1999). Constructing competitive advantage: The role of firm-constituent interactions. Strategic Management Journal, 20, 691-710.

25. Sen, A. (2001). Development as Freedom, Oxford Univ. Press.

26. Tokuda, Akio (2005), The Critical Assessment of the Resource-Based View of Strategic Management: The Source of Heterogeneity of the Firm, Ritsumeikan International Affairs, (3), 125-150.

27. Yasemin, Y., Foss, N., Klein, P. and Mahoney, J, (2006), Entrepreneurship, Subjectivism, and the Resource-Based View: Toward a New Synthesis, Social Science Electronic Publishing Inc, Copenhagen Business School, Denmark.

28. Yang, C., Marlow, P., and Luc, C. (2009). Knowledge Management Enablers in Line Shipping, Transportation Research. 45, 893-903. 